\title{
Dietary Effects of Free Insulin-Like Growth Factor-1 Supplementation On the Production Performance, Serum Tumor Necrosis Factor-A and Nutrient Digestibility in 50-80 Day Old Pigs
}

\section{Darcy Revilleza Pamulaklakin ( $\sim$ drpamulaklakin@up.edu.ph )}

University of the Philippines Los Banos https://orcid.org/0000-0002-0644-3801

\section{Amado Aguilar Angeles}

University of the Philippines Los Banos

Elpidio Malcaba Agbisit

University of the Philippines Los Banos

Francis Carlo Castro Reyes

HP: HP Inc

James William Castro Reyes

San Pablo City Science Integrated High School

\section{Research Article}

Keywords: Insulin-like growth factor-1, tumor necrosis factor-a, digestibility, supplementation

Posted Date: January 27th, 2022

DOI: https://doi.org/10.21203/rs.3.rs-1207666/v1

License: (c) (i) This work is licensed under a Creative Commons Attribution 4.0 International License.

Read Full License 


\section{Abstract}

This study determined the effect of dietary supplementation of insulin-like growth factor-1 (IGF-1) on the production performance, nutrient digestibility, complete blood count (CBC) and serum concentration of tumor necrosis factor-a (TNF-a) on 50 pigs aged 50-80 days (Large white x Landrace; $9.48 \pm 3.59 \mathrm{~kg}$ body weight; $50.6 \mathrm{~d}$ of age), assigned randomly to five treatments $(n=10)$, including one basal $(A=0)$, and four treatment diets with IGF-1 supplementation ( $B=0.25, C=0.5, D=1$, and $E=2 \mathrm{~kg} /$ ton of feed, respectively). Feeding lasted for 28 days, after which 5 pigs from each treatment were selected to undergo nutrient digestibility test. At day 14 and 28, blood samples were extracted for CBC and TNF-a analysis. Results

yielded no significant differences among treatments for body weight, feed intake, average daily gain, and feed conversion ratio. However, the average fecal score for days 1-28, treatment $\mathrm{C}$ differed significantly $(P<0.05)$ being the poorest. There were no significant differences among the treatments on crude protein, crude fat, digestible energy and metabolizable energy. Nursery pigs fed diets with free IGF-1 have lower WBC count $(P<0.05)$ and tended to be higher in RBC count $(P=0.0607)$ at day 15 . Pigs supplemented with free IGF-1 tended to have lower $(P=0.0569)$ TNF-a serum concentrations compared to Control at day 14 . Concluding, the dietary supplementation of IGF-1 does not significantly affect production performance and nutrient digestibility. Collectively, results indicated that supplementation of free-IGF-1 in piglets decreased WBC and serum TNF-a levels while increasing RBC indices in piglet 2 weeks after weaning.

\section{Introduction}

IGF-1 or Insulin-like Growth Factor 1 is a protein molecule with similar structure to Insulin. It is produced primarily by the liver and has been shown to stimulate growth and development as well as immune modulation. Animals naturally produce IGF-1, however, diseases and other stress factors compromise its production leading to poor growth and immune suppression. Insulin and insulin-like growth factor (IGF) receptors have been described in the intestinal epithelium of various species, including the pig. Recent international and local trials showed that dietary supplementation of free IGF-1 reduced length of dry period and backfat thickness loss during lactation in sows and increased weaning weight and survival of piglets (Reyes et al., 2015; Song et al., 2014a and 2015b; Reyes et al., 2016). In the light of these studies, and given that the content of growth factors in sows' milk declines with advancing lactation (Donovan et al., 1994), an opportunity may exist to enhance gut growth and development through supplementation of the newly weaned pig with exogenous growth factors. In an attempt to maintain and enhance intestinal health in pigs and improve productivity in the absence of in-feed antibiotics, researchers have evaluated a wide range of feed additives.. Hence, this study seeks to determine the dietary effects of free IGF-1 supplementation on the production performance, nutrient digestibility, complete blood count (CBC) and serum concentration of tumor necrosis factor a on weaners. The study was conducted at the Institute of Animal Science swine research facility, University of the Philippines Los Baños, Laguna.

\section{Materials And Methods}


A total of 50 crossbred weaner pigs (Large white $x$ Landrace) with an average body weight of $9.48 \pm 3.59$ $\mathrm{kg}$ and 50.6 days of age were used in this study. The population consisted of 26 male pigs with an average body weight of $9.73 \mathrm{~kg}$ and 50.1 days of age and 24 female pigs with an average body weight of $9.20 \mathrm{~kg}$ and 51.1 days of age. These pigs were weaned at 35 days of age, stayed at the farrowing house for another 10 days, and transferred to the nursery building. Pigs were allowed to acclimatize to the new environment and the dietary treatments for 5 days before commencing the feeding trial. At the day of allotment, each pig were weighed and the sex were recorded. The allocations were done by weight and balanced by sex. Ten blocks were made, each having 5 pigs. The pigs were fed with basal diet (control group, treatment A) and 4 diets added with free IGF- 1 at the rate of 0.25 (treatment B), 0.5 (treatment C), 1.0 (treatment D) and 2.0 (treatment E) kg/ton. The basal diet was formulated to meet or exceed nutrient requirements recommended by the Philippine Society of Animal Nutritionists Feed Reference Standards (2010) for swine (Table 1). The free IGF-1 used in this trial was provided by Philchema, Inc. Free IGF-1 (immuTEIN ${ }^{\mathrm{TM}}$ ) is a unique source of activated IGF-1. Its proprietary technology increases the effectiveness of biological proteins which also include growth factors, cytokines, immunoglobulins, transfer factors and other functional proteins that are bioactivated and enhanced in immuTEIN. After allotment, each weaner pig was placed on individual and concrete-floored pens of $2.0 \times 4.2$ meters in size. To allow ad libitum access to feed and water, individual feeder and drinker were installed. The environmental temperature was recorded daily.

\section{Sampling and Measurements}

\section{Study 1: Production Performance, Mortality and Fecal Score}

During allotment, pigs were weighed and designated as day 1 initial weight. Daily feed allowance per pig were recorded including refusal. Thereafter, pig were weighed on days 7,14, 21 and 28 . To obtain average fecal score for each treatment, fecal consistency per pig was assessed and visually scored by 4 independent evaluators twice daily $(9: 00 \mathrm{H}$ and $16: 00 \mathrm{H})$ from days 1 to 28 , based on fecal scoring guide (Figure 1).

\section{Study 2. Nutrient Digestibility}

After 28 days of feeding trial, a total of 15 pigs ( 3 pigs per treatment group) were selected to undergo a nutrient digestibility test, done by allocating 1 metabolic cage per treatment that was implemented in 3 batches. In selecting the first batch of pigs that went into the metabolic cages, pigs from each treatment were weighed - the heaviest pig from each treatment represented the first batch. The same diet was fed and extended for three days, after which, $0.2 \%$ or 2 grams of chromic oxide per $\mathrm{kg}$ of mixed feed was added to serve as an indigestible marker for 8 days. Fecal and urine samples excreted that contained the indigestible marker were collected on day 5, 6,7 and 8 . These samples were pooled and stored at $-20^{\circ} \mathrm{C}$. The same process was done on the second and third batches. The third batch, in turn, represented the lightest of the pigs and it took 24 days to complete the three batches. All fecal samples were oven-dried at $90^{\circ} \mathrm{C}$ for three weeks, grinded, and submitted to the laboratory for crude protein (CP), crude fat (CF) and gross energy determination. Urine samples were processed to obtain gross energy. 


\section{Study 3. Blood Assay}

On day 14 of the feeding trial, blood was extracted from 8 pigs per treatment selected randomly. It was repeated on day 28 on the same pigs. Serum were obtained and stored at $-80^{\circ} \mathrm{C}$. Serum tumor necrosis factor $a($ TNF-a) was determined using ELISA kits specific for TNF- $a$. Similarly, blood samples (10 ml) were collected randomly from 6 pigs per treatment on day 15 and 30. Samples were submitted to a thirdparty laboratory complete blood count (CBC).

\section{Statistical Methods}

Wilk-Shapiro was employed to test the normality followed by the test of homogeneity. The test of homogeneity of variances was done using Sphericity Test. Tukey's Studentized Range (HSD) test was employed for the significance among treatments. When the matrix is symmetric, MANOVA was used, if not, UNIVARIATE was used. Across all studies, $P<0.05$ was applied.

\section{Results}

There were no significant differences among treatments for the body weight, cumulative feed intake (FI), average daily gain (ADG), feed conversion ratio (FCR), and weekly fecal score (Table 2). However, when average fecal score was calculated for the entire period of day $1-28$, treatment $C(P<0.05)$ had the poorest fecal score among the treatments. As shown on Table 3, there were no significant differences among the various treatments for crude protein (CP), CF (Crude Fat), digestible energy (DE) and metabolizable energy (ME). Pigs fed diets with free IGF-1 have lower WBC count $(P<0.05)$ and tended to be higher in RBC count $(P=0.0607)$ at day 15 but showed no treatment differences $(p>0.05)$ at day 30 (Table 4). Other CBC parameters are the same in all treatments $(P>0.05)$. Similarly, pigs supplemented with free IGF-1 tended to have lower $(P=0.0569)$ TNF-a serum concentrations compared to Control at day 14 and also, did not differ $(P>0.05)$ at day 28 (Table 5). There was no significant difference on the serum concentration of TNF- $\mathrm{a}$ among the various treatments in both sampling days.

\section{Discussion}

The current study showed no significant differences on the performance parameters of pigs fed with different levels of supplementation with IGF-1. There was also no significant differences on digestibility across treatments. A direct contrast against growth performance parameters could not be made because, most of the IGF-1 supplementation studies directly measured the capacity and development of the gastro intestinal tract (GIT). In an attempt to explain the results of IGF-1 supplementation, a number of factors have been listed and supported by earlier literature. These factors are the age of the pig used, the influence of IGF-1 Binding Protein (IGFBP) and receptors, the effect of digestion on oral IGF-1 administration, the feed as well the quality of supplement incorporation, the variability of the treatments, experimental error as well as the total number of pigs used on this study. 
The data of Dunshea and Walton in 1995, strongly suggested that the subcutaneous infusion of IGF-1 analogue on pigs aged 0-27 days expressed not only increased piglet growth rate (ADG) in late lactation, but also increased the growth of small intestine, spleen and pancreas. In this instance, the authors suggested that the spleen size seen may reflect an enhanced immune response. In 1996, Burin et al., conducted a study involving oral supplementation of human recombinant IGF-1. Their results demonstrated that oral administration of human recombinant IGF-I during the first 4 days after birth significantly increased small intestinal mucosal growth in formula-fed neonatal pigs. Beneficial effects of orally administered IGF-I have been reported in neonatal piglets by Houle et al., (2000) and Burin et al., (2001). However, no effects of oral IGF-1 on serum concentration, overall body weight, or growth of tissues other than the intestine were reported. Most recently, Donovan and Monaco, in 2004 concluded that, in general, there is no effect of oral IGF-1 on serum concentration, overall body weight or growth of tissues other than the intestine in neonatal pigs. On the current study, overall average age of pigs used at the beginning of the experiment was 50.6 days, the youngest pig recorded was 44 days while the oldest was 52 days. The average weight was $9.48 \mathrm{~kg}$, with the lightest recorded at $5.60 \mathrm{~kg}$ and heaviest at 12.78 $\mathrm{kg}$. The age of the pig is a major difference on from the studies cited, which were conducted on neonatal pigs, 27 days being the oldest animal. Age has a linear effect towards intestinal development (Efird et al., 1982) thereby directly proportional or translated into growth performance of the pigs.

\section{IGF-1 Binding Protein and Receptors}

To be able to express its effect, IGF-1 needs binding protein. Insulin-like growth factor (IGF) action is influenced by the insulin-like growth factor binding proteins (IGFBPs). Binding Proteins (BP) control the distribution, function and activity of IGF-1 in vivo and are produced and expressed in at least one form in almost all tissues. It is thought that mechanisms controlling the expression of BPs during various physiological states will determine whether IGFs, both IGF-1 and IGF-2, have effects on IGF- mediated growth (Hossner et al., 1997). According to Lee et al., 1993, IGF-I and IGFBP-3 concentrations in porcine serum are low during fetal life, but they increase in postnatal life. On the other hand, IGFBP-2 is present in porcine follicular fluid (Monschein et al. 1990), it decreases in postnatal life (Russell and Van Wyk 1995; Lee et al., 1993). IGF receptors (Fernandez-Moreno et al., 1987) types I and II (Schober et al., 1990; Young et al., 1990 ) have been detected along the entire neonatal intestine. Schober et al. (1990) concluded that in the piglet, binding of IGF-I to intestinal receptors was highest at birth, declined at 3 and 5 day postpartum, but recovered by 21 day postpartum. This may very well explain the potency of IGF- 1 on the neonatal pigs. In addition, receptor binding is higher in newborn animals and declines with age (Li et al., 2006 and Donovan et al., 2004). On this current study, however, these binding proteins and receptors were not studied nor quantified, such that no direct conclusion can be made on the its role on the magnitude of effect during IGF-1 supplementation. It could only be said, based on the above publications that, IGF-1 binding proteins (IGFBP) and receptors mitigates the effects of IGF-1. On this study, however, it is impossible to say whether or not that there is sufficient amount of serum binding proteins and receptors or even their total absence or presence in the circulation during the phase of production and age of the pig utilized. It could only be strongly suggested, based on the above literature, that, binding protein's availability as well as the receptors, will dictate the site and mechanism of action of IGF-1. Thereby 
understanding that binding proteins and receptors are paramount to IGF-1 to cause an effect, it will nonetheless assist on explaining the results of this study.

\section{Effect on Digestion of Orally Administered IGF-1}

Burrin et al., in 1992 concluded that orally administered IGF-1 is stable to digestion during neonatal stage of the piglet. According to Schoknecht et al. (1993), exogenous IGF-1 (or analogue) treatment given to pigs does not feedback in a negative manner to inhibit endogenous IGF-1 secretion, thereby allowing the growth-promoting properties of this hormone to be expressed, his conclusion formed the basis of dose dependent IGF-1 feeding trials. However IGF-1 is rapidly degraded within the adult gastrointestinal tract (Xian et al., 1995; Rao et al., 1998), but it appears to survive digestion and exert effects within the neonatal intestine. On the current study, we cannot entirely conclude whether or not the orally supplemented IGF-1 was affected by gastro intestinal secretions. We can only refer to the abovementioned studies that digestion will exert an effect on the availability of circulating IGF-1, in particular with older pigs.

\section{Other Factors}

The health and nutritional status of the animal may very well affect the magnitude of response. The absence of severe diarrhea is suggestive of a mature GIT, absence of pathogenic challenge or stable immune system, thus none or minimum effect of supplementation can be achieved on an apparently healthy animals. The average fecal score of Group C (IGF-1 at $0.5 \mathrm{~kg} / \mathrm{ton}$ ) which is statistically significant has the value of 1.77 which leaned towards moist feces, thereby negating the ability of the treatment to reduce cases of diarrhea. The overall significance of the fecal score is with the time factor. When the analysis was done per week, no significant difference among treatments were observed. However, when day 1 to 28 was treated as one period, statistical difference was observed. Interestingly, the other treatments are statistically the same. However, this could be taken as an important factor for further studies for the optimum inclusion rate for the free IGF-1 on diets. Again, it must be noted that the experiment was conducted in weaned pigs that were apparently healthy and that pathogenic infection is low or none at all, with no other known disease challenge that manifested at the start of the feeding trial. The cause for these findings were, the least to say, unclear, but may be attributed to the timing, the quantity of diet obtained and amount consumed, the quality of IGF-1 incorporation in the diet, dietary composition, and age at weaning, that constitute differences on absorptive function in the GIT. Some of these are clearly the limitations of this study. In general, it is well-accepted that response to feed additives is dependent on age of the pig, disease level, environmental factors, and type of diet. It may be possible that at this stage of production, the pig has been well acclimatized on the diet showing consistent feed intake and weight gain. Healthy and well-fed animals with appropriate management, favorable environment, and minimal stress are generally less responsive to a feed additive.

\section{CBC and TNF-a Concentration}


Piglets are known to be susceptible to enteric infections due to not fully developed immunity and by contact to pathogens naturally present in the environment. (Stokes et al., 2004; Petrovic et al., 2009). IGF1 has been proven effective in enhancing immunity of piglets by stimulating T-lymphocytes and natural killer cells (Brocardo et al., 2001; Smith, 2010), gastrointestinal maturation (Xu et al., 1994; Hartke et al., 2005), and nutrient absorption (Alexander and Carey, 1999). Enhancement of immunity can also be related to previous studies on dietary supplementation of free IGF-1 in sows which resulted to increase in survivability of piglets (Reyes et al., 2015; Song et al., 2014a and 2015b; Reyes et al., 2016). In the present study, nursery pigs at day 15 that were not supplemented with free IGF-1 have WBC levels higher than the normal values for pigs which is (24.86 vs. $11-22 \times 10^{3} / \mu \mathrm{L}$; The Merck Veterinary Manual, 2016). This demonstrates the potential of supplementing free IGF-1 in enhancing immunity of nursery pigs during challenged conditions. The involvement of IGF-1 on red blood cell production has already been established (Miyagawa et al., 2000; Kling et al., 2006). The increased rate of RBC production leads to better oxygen transport in blood. In a study that involved cardiopulmonary bypass of piglets, intravenous infusion of IGF-1 improved oxygen transport by reducing oxygen consumption as well as increasing cardiac output and oxygen delivery during the first 6 hours post-operation (Li et al., 2004). Better oxygen transport promotes anabolism such as muscle tissue growth. Improvement in RBC indices has potential to improve growth rate and health of pigs even during times of stress. Exposure to micro-organisms commonly elicit the production of cytokines. These soluble factors enhance several innate immune functions that aim to limit the spread of infection. The onset of production of these cytokines is rapid, and several of them may reach systemic levels during a short period after infection. Thus, cytokines can serve as markers for ongoing infections and be used to discriminate between infections of bacterial or viral origin. Several bacterial compounds (peptidoglycan, lipotechoic acid, polysaccharide, various toxins, heat shock proteins, and super antigens) can induce the production of pro-inflammatory cytokines (Degre, 1996) and consequently also infections with Gram-positive bacteria can result in measurable blood levels of TNF-a , IL-6, IL-8, and G-CSF (Kragsbjerg et al., 1996). One study on porcine intestinal ion transport shows that TNF- a may be involved in the stimulation of $\mathrm{NaCl}$ secretion in the ileum (Alexander et al., 2001, 2002 and Kandil et al., 1994). Their data suggest that the increased expression of TNF- a may be implicated in the development of post-weaning diarrhea. Pro-inflammatory cytokines, such as TNFa, play a vital role in the normal host resistance to infection, serving as immunomodulators and as mediators of inflammatory signs (Kiarie et al., 2009) thus, identifying the changes in serum concentration of which could exhibit the effect of free IGF-1 supplementation on inflammatory response. The results illustrated that there is no statistical difference between the treated and non-treated groups with regards to the TNFa $(\mathrm{pg} / \mathrm{ml})$ serum concentration. This could imply that, since there are no severe clinical signs of diarrhea within the control and treatment groups, an immunomodulatory response through the pro-inflammatory cytokine, TNF-a, was demonstrated at lower values. A study reported by Nyachoti et al. (2012) reported that increased TNF- $a$ increased from 111.4 to $162.1 \mathrm{pg} / \mathrm{ml}$ upon ETEC challenge which proves that during inflammatory encounter, TNFa serum concentration will be on upsurge. In a study done by Kruse et al. (2008), TNF-a increased in all animals after inoculation of Brachyspira hyodysenteriae, with a peak at $300 \mathrm{pg} / \mathrm{ml}$. It must be emphasized that the release of TNF- $a$, and other inflammatory cytokines, are rapid and induced early in a disease or injury process. However, it's not exclusive to viral and bacterial 
infections. A study by Pie et al. (2004) suggested that Cytokines play a central role in immune cell response, but they also participate in the maintenance of tissue integrity. Changes in the cytokine network of the pig gut may be expected at weaning, because abrupt changes in dietary and environmental factors lead to important morphological and functional adaptations in the gut. The current results, could suggest that the TNF-a levels present on the serum could indicate an inflammatory response or could be attributed to weaning. Stress brought by weaning commonly induce production of pro-inflammatory cytokines, such as TNF-a (Kiarie et al., 2009). Upon the presence of inflammation, nursery pigs supplemented with free IGF-1 could be able to immunomodulate or decrease the level of serum TNF-a , therefore reducing the signs of inflammation. However, attributing these values entirely to infection could not be determined due to the numerous factors affecting TNF-a release.

Concluding, the dietary supplementation of insulin growth factor-1 (IGF-1) had no significant effect on the production performance, serum concentration of tumor necrosis factor alpha and nutrient digestibility in weaned pigs. Collectively, results indicated that supplementation of free-IGF-1 in piglets decreased WBC and serum TNF-a levels while increasing RBC indices in piglets 2 weeks after weaning. We can also measure earlier (e.g. day 7) to see possible greater response. It can be concluded that supplementation of free-IGF-1 can lessen the negative impact of post-weaning stress particularly response to pathogen infection and inflammation. The study offered suggestive evidence for the role of dietary supplementation of IGF-1 on fecal consistency. No diarrhea was observed on the entire trial period, although pigs fed with control diet yielded the same fecal score. Further study should be focused on this potential. The study appears to support the argument that age of the pig is an important factor to consider. This would suggest that future research may done on neonatal pigs or at pre weaning period with a considerable population. It is relevant to relate levels of IGF-1 in the circulation, thus, blood profiling can be done periodically during the trial period. Future research into IGF-1 supplementation can also be done by measuring the weight and length of the small intestine, furthermore a histopathological examination can be performed to characterized the villous height and crypt depth. Modification of the basal diet can also be suggested. Other inflammatory cytokines can also be included as a measure of inflammation.

\section{Declarations}

\section{Acknowledgement}

This study will not be completed without the invaluable assistance from Philchema Incorporated, Department of Science and Technology - Philippine Council for Agriculture, Aquatic and Natural Resources Research and Development (PCAARRD) and the Institute of Animal Science-University of the Philippine, Los Baños, much appreciation is given to the people behind these institutions.

\section{i. Funding}

This work was supported by the Philchema Incorporated, Institute of Animal Science, College of Agriculture and Food Science, University of the Philippines Los Baños and the Graduate Research and 
Education Assistantship for Technology Program of the Department of Science and TechnologyPhilippine Council for Agriculture, Aquatic and Natural Resources Research and Development.

\section{ii. Conflicts of interest/Competing interests}

The authors have no relevant financial or non-financial interests to disclose.

\section{iii. Ethics approval}

The procedure used in this study adhere to the tenets and approval was granted by the Institutional Animal Care and Use Committee (IACUC) of the University of the Philippines Los Baños.

\section{iv. Consent to participate}

Not applicable.

\section{v. Consent for publication}

Not Applicable

\section{vi. Availability of data and material}

The datasets generated during and/or analyzed during the current study are available from the corresponding authors on reasonable request.

\section{vii. Code availability}

Not Applicable

\section{viii. Authors' contributions}

All authors contributed to the study conception and design. All authors read and approved the final manuscript.

\section{References}

1. Alexander, A. N. and Carrey, H.V., 1999. Oral IGF-I enhances nutrient and electrolytes absorption in neonatal piglet intestine. American Journal of Physiology, 277:G619-G625

2. Alexander, A.N. and Carrey, H.V., 2001. Involvement of PI 3-kinase in IGF-I stimulation of jejunal Na+K+-APTase activity and nutrient absorption. American Journal of Physiology, 277:G619-G625

3. Alexander, A. N. and Carrey, H. V., 2002. Insulin-like growth factor- I stimulates Na+-dependent glutamine absorption in piglet enterocytes. Digestive Diseases and Sciences, 47:1129-1134

4. Brocardo M.G.,Chillaci R., Galeano A., Radrizzani M., White V., Guerrico A. G.,Santa-Coloma T. A. and Roldan A. 2001. Early effects of insulin-like growth factor-1 in activated human T lymphocytes. 
Journal of Leukocyte Biology, 70:297-305

5. Burrin D. G., Petersen Y.,Stoll B. and Sangild P. 2001. Glucagon-like peptide 2: a nutrient-responsive gut growth factor. The Journal of Nutrition, 131: 709-712

6. Burrin D. G., Shulman R. J., Reeds P.J., Davis T. A. and Gravitt K. R. 1992. Porcine colostrum and milk stimulate visceral organ and skeletal muscle protein synthesis in neonatal piglets. The Journal of Nutrition,122:1205

7. Burrin D. G., Wester T. J., Davis T. A., Amick S. and Heath, J.P. 1996. Orally administered IGF-I increases intestinal mucosal growth in formula-fed neonatal pigs. American Journal of Physiology, 270: R1085-91

8. Degree' M. 1996. Interferons and other cytokines in bacterial infections. Journal of Interferon and Cytokine Research, 16:417-426

9. Donovan S.M., Mcneill L. K., Jimenez-Flores R. and Odle, J .1994. Insulin-like growth factors and IGF binding proteins in porcine serum and milk throughout lactation. Pediatric Research, 36:59-168

10. Donovan S.M. and Monaco M. H., 2004. Insulin-like growth factor-1 and piglet intestinal development. Journal of Dairy Science, 87: E47-E54

11. Dunshea F. R. and Walton P.E., 1995. Potential of exogenous metabolic modifiers for the pig industry. In: Hennessy, D.P., Cranwell, P.D. (Eds), Manipulating Pig Production V. Australian Pig Science Association, Werribee, Victoria, Australia, p 42-51

12. Erfid R. C., Armstrong W. D. and Herman D. L., 1982. The Development of Digestive Capacity in Young Pigs: Effects of Weaning Regimen and Dietary Treatment. Journal of Animal Science, 55:1370-1379

13. Fernandez-Moreno M. D., Serrano-Rios M. and Prieto J.C., 1987. Identification of insulin-receptors in epithelial cells from duodenum jejunum, ileum, caecum, colon and rectum in the rat. Diabetes and Metabolism Journal, 13:135

14. Hartke J.L., Monaco M. H., Wheeler M. B. and Donovan S. M. 2005. Effect of a short-term fast on intestinal disaccharidase activity and villus morphology of piglets suckling insulin-like growth factorI transgenic sows. Journal Of Animal Science, 83:2404-2413

15. Hossner K. L., McCusker R. H. and Dodson M. V. 1997: Insulin-like growth factors and their binding proteins in domestic animals. Journal of Animal Science, 64:1-15

16. Houle V. M., Laswell S. C., Freund G. G., Dudley M. A. and Donovan S. M. 2000. Investigation of three doses of oral insulin-like growth factor-I on jejunal lactase phlorizin hydrolase activity and gene expression and enterocyte proliferation and migration in piglets. Pediatric Research, 48:497-503

17. Kandil H. M., Berschneider H. M. and Argenzio R. A. 1994. Tumour necrosis factor alpha changes porcine intestinal ion transport through a paracrine mechanism involving prostaglandins. Gut, 35: 934-940

18. Kiarie E., Slominski B. A., Krause D. O. and Nyachoti C. M. 2009. Acute phase response of piglets fed diets containing non starch polysaccharide hydrolysis products and egg yolk antibodies following an oral challenge with Escherichia coli (K88). Canadian Journal of Animal Science, 89:353-360 
19. Kragsbjerg P., Holmberg H. and Vikerfors T. 1996. Dynamics of blood cytokine concentrations in patients with bacteremic infections. Scandinavian Journal of Infectious Disease, 28:391-398

20. Kruse R., Essen-gustavsson B., Fossum C. and Jensen-Waern M. 2008. Blood concentrations of cytokines IL-1beta,IL-6,IL-10,TNF-alpha and IFN-gamma during experimentally induced swine dysentery. Acta Veterinaria Scandinavica. 58:1-7

21. Lee C.Y., Chung C. S. and Simmen F. A. 1993. Ontogeny of the porcine insulin-like growth factor system. Endocrinology, 93: 71-80

22. Li X., Yin J., Li D., Chen X., Zang J. and Zhou J. 2006. Dietary supplementation with zinc oxide increases IGF-1 and IGF-1 receptor gene expression in the small intestine of weanling piglets. The Journal of Nutrition, 0022-3166/06:1786-89

23. Li J., Stenbog E., Bush A., Grofte T., Redington A. and Penny D. J. 2009.Insulin-like growth factor 1 improves the relationship between systemic oxygen consumption and delivery in piglets after cardiopulmonary bypass. The Journal of Thoracic and Cardiovascular Surgery, 127(5):1436-1441

24. Mondschein J. S., Smith S. A. and Hammond J. M. 1990. Production of insulin-like growth factor binding proteins (IGBPS) by porcine granulosa cells: Identification of IGFBP-2 and -3 and regulation by hormones and growth factors. Endocrinology, 127: 2298-2306

25. Nyachoti C. M., Kiarie E. Bhandari S. K., Zhang G. and Krause D. 0. 2012. Weaned pig responses to Escherichia coli K88 oral challenge when receiving a lysozyme supplement. Journal of Animal Science, 90:252-260

26. Petrovic V., Novotny J., Hisira V., Link R., Leng L. and Kovac G. 2009. The Impact of Suckling and Post-weaning Period on Blood Chemistry of Piglets. Acta Veterinaria Brno, 78:365-371

27. Pie' S., LalleS. J. P. , BlazyF. , LaffieJ. , Seve B. and Oswald J. P. 2004. Weaning is associated with an upregulation of expression of inflammatory cytokines in the intestine of piglets. The Journal of Nutrition. 134: 641-647

28. Rao R. K., Philipps A. F., Williams C. S., McCracken D. M. and Koldovsky O. 1998. Luminal stability of insulin-like growth factors I and II in developing rat gastrointestinal tract. Journal of Pediatric Gastroenterology and Nutrition, 26:179-185

29. Reyes F.C.C., Cardona J.K.M., Angeles E.P., Regaspi A.F.S., Magpantay V.A., Cabigting S.A., Bagui N.J.G., Briones B.H.I., Plata L.M. 2015. Effect of Activated Insulin-like Growth Factor I (IGF-1) on reproductive performance of lactating sows. Proceedings of the $52^{\text {nd }}$ Philippine Society of Animal Science Scientific Seminar and Annual Convention, Palawan, Philippines, p10.

30. Reyes F.C.C., Cardona J.K.M., Angeles E.P., Regaspi A.F.S., Dimaiwat M.I., Aldemita J.T.N., Magpantay V.A., Cabigting S.A., Bagui N.J.G., Briones B.H.I., Plata L.M., Casebolt B.D. 2016. Dietary Supplementation of Activated IGF-1 during Gestation and Lactation Affects Sow and Piglet Performance. Proceedings of the 17th Asian-Australasian Association of Animal Production Societies Animal Science Congress, Fukuoka, Japan, p1356-1359.

31. Russell W. E. and Van Wyk J. J., 1995. Peptide growth factors. Endocrinology (ed LJ De Groot), 25902623pp 
32. Schober D.A., Simmen F. A., Hadsell D. L. and Baumrucker C. R. 1990. Perinatal expression of type I IGF receptors in porcine small intestine. Endocrinology, 126:1125-32

33. Schoknecht P. A., Ebner S., Skottner A., Burrin D. G., Davis T. A. and Pond W. G. 1993. Exogenous IGF1 increased early neonatal weight gain in progeny of protein-restricted sows. Journal of Animal Science, 71: 134

34. Smith T.J. 2010. Insulin-like growth factor-I regulation of immune function: a potential therapeutic target in autoimmune diseases. Pharmacology Review, 62:199-236.

35. Stokes C. R., Bailey M., Haverson K., Harris C., Jones P., Inman C., Pie S., Oswald I.P., Williams B. A., Akkermans A. D. L., Sowa E., Othkotter H. J. and Miller B. G. 2004. Postnatal development of intestinal immune system in piglets: implications for the process of weaning. Animal Research, 53 : $325-334$.

36. Song R., Friesen K., Fongemie R. and Morris A. Effect of feeding betaGRO to sows, nursery and growfinish pigs (breed to slaughter) 2014a. http://www.nutriquest.com. Accessed 21 March 2015

37. Song R., Friesen K., Fongemie R. and Morris A. 2014b. Effect of feeding betaGRO to sows and nursery pigs (mating through nursery) 2014b. http://www.nutriquest.com. Accessed March 21, 2015

38. The Merck Veterinary Manual. 2016. $11^{\text {th }}$ ed. Merck and Co, Inc. Kenilworth, NJ, USA.

39. Xian C. J., Shoubridge C. A. and Read L. C. 1995. Degradation of IGF-I in the adult rat gastrointestinal tract is limited by a specific antiserum or the dietary protein casein. Journal of Endocrinology, 146:215-225

40. Xu R. J, Mellor D. J., Birtles M. J., Breier B. H. and Gluckman P. D. 1994. Effects of oral IGF-1 or IGF-11 on digestive organ growth in newborn pigs. Biology of the Neonate, 66: 280-287

41. Young G. P., Taranto T. M., Jones H. A., Cox A. J., Hogg A. and Werther G. A.. 1990. Insulin-like growth factors in the developing and mature rat small intestine: receptors and biological actions. Digestion. $46: 240$

\section{Tables}

Table 1. Composition and nutrient levels of basal diets 


\begin{tabular}{|c|c|c|}
\hline \multicolumn{2}{|l|}{ Ingredients } & Content (\%) \\
\hline \multicolumn{2}{|l|}{ Yellow Corn } & 45.48 \\
\hline \multicolumn{2}{|l|}{ Soybean Meal, US } & 25.00 \\
\hline \multicolumn{2}{|l|}{ Sweet Whey } & 11.50 \\
\hline \multicolumn{2}{|l|}{ Rice Bran } & 7.50 \\
\hline \multicolumn{2}{|l|}{ Crude Coconut Oil } & 4.45 \\
\hline \multicolumn{2}{|l|}{ Limestone, fine } & 1.70 \\
\hline \multicolumn{2}{|c|}{ Mono-Dicalcium Phosphate } & 1.68 \\
\hline \multicolumn{2}{|l|}{ L-Lysine $\mathrm{HCl}$} & 0.69 \\
\hline \multicolumn{2}{|l|}{ Salt, lodized } & 0.40 \\
\hline \multicolumn{2}{|l|}{ DL-Methionine } & 0.31 \\
\hline \multicolumn{2}{|l|}{ Acidifier } & 0.30 \\
\hline \multicolumn{2}{|l|}{ L-Threonine } & 0.30 \\
\hline \multicolumn{2}{|l|}{ Toxin Binder } & 0.20 \\
\hline \multicolumn{2}{|l|}{ Choline Chloride, $50 \%$} & 0.14 \\
\hline \multicolumn{2}{|l|}{ Vitamin Premix ${ }^{1}$} & 0.10 \\
\hline \multicolumn{2}{|l|}{ Mineral Premix ${ }^{2}$} & 0.10 \\
\hline \multicolumn{2}{|l|}{ Mold Inhibitor } & 0.05 \\
\hline \multicolumn{2}{|l|}{ Copper Sulfate } & 0.05 \\
\hline \multicolumn{2}{|l|}{ Zinc Oxide } & 0.03 \\
\hline \multicolumn{2}{|l|}{ Antioxidant } & 0.01 \\
\hline \multicolumn{2}{|l|}{ Tryptophan } & 0.01 \\
\hline Metabolizable Energy & Kcal,kg & $3,250.00$ \\
\hline Crude Protein ${ }^{3}$ & $\%$ & 18.00 \\
\hline Crude Fiber & $\%$ & 2.68 \\
\hline Crude Fat $^{3}$ & $\%$ & 7.43 \\
\hline Calcium & $\%$ & 1.00 \\
\hline Avail. Phosphorus & $\%$ & 0.50 \\
\hline Lactose & $\begin{array}{c}\% \\
3 / 19\end{array}$ & 7.50 \\
\hline
\end{tabular}




\begin{tabular}{lcl}
\hline Starch & $\%$ & 30.45 \\
\hline Digestible Lysine & $\%$ & 1.40 \\
\hline Digestible Methionine & $\%$ & 0.56 \\
\hline Digestible Met+Cys & $\%$ & 0.82 \\
\hline Digestible Threonine & $\%$ & 0.91 \\
\hline Digestible Tryptophan & $\%$ & 0.20 \\
\hline Digestible Valine & $\%$ & 0.80
\end{tabular}

1 Vitamin Premix: A (50,000,000 IU), D (10,000,000 IU), E (200,000 mg), K3 (10,000 mg), B1 (10,000 mg), B2 (25,000 mg), B3 (170,000 mg), B5 (70,000 mg), B6 (20,000 mg), B9 (5,000 mg); B12 (100 mg), and Biotin (1,000 mg).

2 Mineral Premix: Iron (80,000 mg), Zinc (140,000 mg), Manganese (40,000 mg), Copper (100,000 mg), lodine (400 mg), Selenium (300 mg), and Cobalt (1,600 mg).

3 Proximate Analysis: CP (17.99\%) and CFat (6.28\%).

Table 2. Mean values of weekly body weight, fecal score, cumulative feed intake ( $\mathrm{FI})$, average daily gain (ADG), and feed conversion ratio (FCR) of 50 individually caged pigs fed with diets supplemented with and without free IGF-1. 
Treatment levels of IGF-1, kg/ton

\begin{tabular}{|c|c|c|c|c|c|c|c|c|}
\hline \multicolumn{2}{|c|}{ Response Variable } & \multirow{2}{*}{$\begin{array}{l}A \\
11.58\end{array}$} & \multirow{2}{*}{$\begin{array}{l}\text { B } \\
11.34\end{array}$} & \multirow{2}{*}{$\begin{array}{l}\text { C } \\
11.50\end{array}$} & \multirow{2}{*}{$\begin{array}{l}\text { D } \\
12.20\end{array}$} & \multirow{2}{*}{$\begin{array}{l}E \\
12.19\end{array}$} & \multirow{2}{*}{$\begin{array}{l}\text { SEM } \\
0.5519\end{array}$} & \multirow{2}{*}{$\begin{array}{l}P \text {-value } \\
0.7090\end{array}$} \\
\hline Body Weight, kg & d $1-7$ & & & & & & & \\
\hline & d 1-14 & 14.56 & 14.87 & 14.61 & 15.58 & 15.64 & 0.6715 & 0.6583 \\
\hline & d $1-21$ & 18.41 & 19.36 & 19.56 & 20.41 & 20.66 & 0.8854 & 0.4037 \\
\hline & d 1-28 & 23.45 & 23.80 & 24.85 & 26.20 & 26.00 & 1.1075 & 0.2977 \\
\hline \multirow[t]{4}{*}{$\mathrm{Fl}, \mathrm{kg}$} & d 1-7 & 4.09 & 3.97 & 4.09 & 4.18 & 4.21 & 0.2043 & 0.9368 \\
\hline & d 1-14 & 9.64 & 9.81 & 9.58 & 10.12 & 10.30 & 0.4530 & 0.7462 \\
\hline & d $1-21$ & 16.82 & 17.42 & 16.85 & 18.07 & 18.45 & 0.8309 & 0.5381 \\
\hline & d $1-28$ & 22.23 & 22.21 & 21.88 & 23.19 & 23.69 & 0.7163 & 0.3520 \\
\hline \multirow[t]{4}{*}{$A D G, g$} & d 1-7 & 312 & 315 & 305 & 341 & 358 & 25.70 & 0.5300 \\
\hline & d 1-14 & 369 & 410 & 375 & 412 & 425 & 23.37 & 0.2718 \\
\hline & d 1-21 & 429 & 487 & 486 & 504 & 523 & 27.10 & 0.1358 \\
\hline & d $1-28$ & 502 & 524 & 553 & 585 & 583 & 28.94 & 0.1522 \\
\hline \multirow[t]{4}{*}{ FCR, kg } & d 1-7 & 1.93 & 1.86 & 1.99 & 1.87 & 1.73 & 0.1361 & 0.7425 \\
\hline & d 1-14 & 1.89 & 1.74 & 1.84 & 1.81 & 1.73 & 0.0762 & 0.5754 \\
\hline & d 1-21 & 1.89 & 1.71 & 1.67 & 1.76 & 1.68 & 0.0664 & 0.1298 \\
\hline & d $1-28$ & 1.63 & 1.53 & 1.46 & 1.46 & 1.46 & 0.0817 & 0.5065 \\
\hline \multirow[t]{4}{*}{ Fecal Score } & d 2-7 & 1.63 & 1.76 & 1.96 & 1.84 & 1.76 & 0.1587 & 0.3037 \\
\hline & d 8-14 & 1.56 & 1.63 & 1.69 & 1.57 & 1.43 & 0.0947 & 0.2455 \\
\hline & d 15-21 & 1.63 & 1.58 & 1.65 & 1.50 & 1.55 & 0.1109 & 0.0904 \\
\hline & d $16-28$ & 1.38 & 1.41 & 1.42 & 1.35 & 1.34 & 0.0750 & 0.2822 \\
\hline Ave. Fecal Score & d 1-28 & $1.6^{\mathrm{a}}$ & $1.67^{a}$ & $1.77^{b}$ & $1.64^{\mathrm{a}}$ & $1.59^{a}$ & 0.1476 & 0.0388 \\
\hline
\end{tabular}

$a-b$ Values in the same row with different superscripts are statistically significant $(P<0.05)$ Table 3. Mean values of crude protein (CP), crude fat (CF), metabolizable energy (ME) and digestible energy (DE) digestibility of 15 individually caged pigs fed with diets supplemented with and without free IGF-1. 
Treatment levels of IGF-1, kg/ton

\begin{tabular}{|c|c|c|c|c|c|c|c|}
\hline Item & A & B & C & D & $\mathrm{E}$ & SEM & $P$-value \\
\hline Crude Protein (CP), \% & 18.61 & 17.52 & 17.32 & 17.07 & 17.61 & 0.7535 & 0.6684 \\
\hline $\begin{array}{l}\text { Coefficient of } \\
\text { Digestibility for } \mathrm{CP}, \%\end{array}$ & 0.8322 & 0.8495 & 0.8616 & 0.8750 & 0.8510 & 0.02 & 0.7772 \\
\hline Digestible CP, \% & 14.97 & 15.28 & 15.50 & 15.74 & 15.31 & 0.43 & 0.7772 \\
\hline Crude Fat (CFat), \% & 4.62 & 3.72 & 3.03 & 3.77 & 4.39 & 0.3825 & 0.1117 \\
\hline Gros Energy (GE), kcal & 3945.88 & 3945.88 & 3945.88 & 3945.88 & 3945.88 & & \\
\hline $\begin{array}{l}\text { Coefficient of } \\
\text { Digestibility for } \\
\text { Digestible Gross } \\
\text { Energy (DE), \% }\end{array}$ & 0.8660 & 0.8740 & 0.8861 & 0.8934 & 0.8727 & 0.02 & 0.7835 \\
\hline Digestible GE, kcal & 3417.00 & 3448.67 & 3496.36 & 3525.17 & 3443.42 & 66.55 & 0.7835 \\
\hline $\begin{array}{l}\text { Coefficient of } \\
\text { Digestibility for } \\
\text { Metabolizable Gross } \\
\text { Energy (ME), \% }\end{array}$ & 0.8545 & 0.8684 & 0.882 & 0.8905 & 0.8657 & 0.02 & 0.6224 \\
\hline $\begin{array}{l}\text { Metabolizable GE, } \\
\text { kcal }\end{array}$ & 3371.86 & 3426.47 & 3480.17 & 3513.75 & 3415.75 & 67.75 & 0.6224 \\
\hline
\end{tabular}

Table 4. Mean values of complete blood count (CBC) of 40 individually caged pigs fed with diets supplemented with and without free IGF-1. 
Treatment levels of IGF-1, kg/ton
A
B
C
D
E
SEM
p-value

WBC

Day 15

Day 30

Neutrophils

Day 15

Day 30

Lymphocytes

Day 15

Day 30

Neutrophil:Lymphocyte

Day 15

Day 30

Monocytes

Day 15

Day 30

Eosinophils

\begin{tabular}{|l|}
\hline Day 15 \\
\hline Day 30 \\
\hline Basophils \\
\hline
\end{tabular}

Day 15

Day 30

RBC

\begin{tabular}{|llllllll|}
\hline Day 15 & 6.73 & 6.70 & 7.07 & 7.37 & 7.00 & 0.1706 & 0.0607 \\
\hline Day 30 & 6.66 & 6.90 & 6.90 & 6.90 & 6.88 & 0.5933 & 0.5586 \\
\hline Hgb & & & & & & & \\
\hline Day 15 & 9.85 & 9.71 & 10.47 & 10.47 & 10.40 & 0.4167 & 0.5446 \\
\hline
\end{tabular}




\begin{tabular}{|llllllll|}
\hline Day 30 & 9.65 & 9.92 & 10.42 & 9.90 & 9.83 & 2.2756 & 0.4170 \\
\hline PCV & & & & & & & \\
\hline Day 15 & 38.17 & 37.28 & 40.15 & 40.83 & 39.00 & 1.5890 & 0.5156 \\
\hline Day 30 & 35.50 & 37.33 & 38.33 & 36.67 & 36.33 & 2.6083 & 0.6649 \\
\hline MCV & & & & & & & \\
\hline Day 15 & 55.90 & 55.06 & 56.67 & 55.42 & 56.12 & 1.6468 & 0.9644 \\
\hline Day 30 & 53.18 & 54.58 & 55.60 & 52.97 & 53.63 & 0.6784 & 0.6504 \\
\hline MCH & & & & & & & \\
\hline Day 15 & 16.81 & 14.43 & 14.70 & 14.26 & 14.88 & 1.0383 & 0.4334 \\
\hline Day 30 & 14.52 & 14.76 & 15.10 & 14.29 & 14.60 & 0.2794 & 0.9242 \\
\hline MCHC & & & & & & & \\
\hline Day 15 & 27.08 & 26.28 & 26.10 & 25.48 & 26.38 & 0.6267 & 0.4609 \\
\hline
\end{tabular}

a-bValues in the same row with different superscripts are statistically significant $(P<0.05)$

Table 5. Mean values of Serum TNF a concentration $(\mathrm{pg} / \mathrm{ml})$ of 40 individually caged pigs fed with diets supplemented with and without free IGF-1.

Treatment levels of IGF-1, kg/ton

\begin{tabular}{llllllll}
\hline Item & A & B & C & D & E & SEM & $P$-value \\
\hline d 14 & 106.6275 & 90.3681 & 83.2751 & 79.2821 & 86.9049 & 6.2168 & 0.0569 \\
\hline d 28 & 136.8150 & 85.9454 & 87.0546 & 115.0738 & 95.7091 & 16.1587 & 0.1860 \\
\hline
\end{tabular}

\section{Figures}

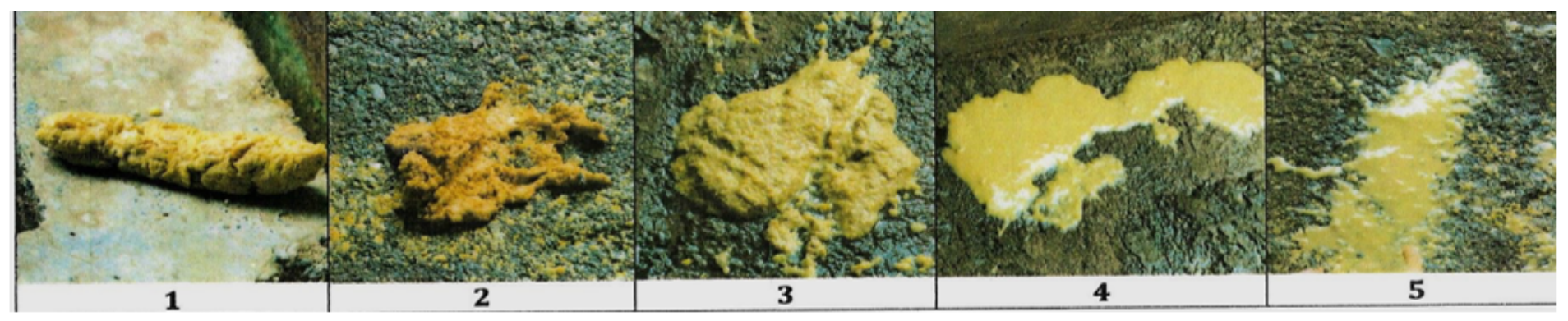

Figure 1 
Fecal scoring guide used $(1=$ normal, $2=$ moist, $3=$ mild diarrhea, $4=$ severe diarrhea, $5=$ watery diarrhea) 